\title{
Know thyself: NK-cell inhibitory receptors prompt self-tolerance, education, and viral control
}

\section{William T. Nash ${ }^{1,2}$, Jeffrey Teoh ${ }^{1,2}$, Hairong Wei ${ }^{2,3}$, Awndre Gamache ${ }^{1,2}$ and Michael G. Brown ${ }^{1,2,3 *}$}

1 Department of Microbiology, Immunology, and Cancer Biology, School of Medicine, University of Virginia, Charlottesville, VA, USA

2 Beirne B. Carter Center for Immunology Research, School of Medicine, University of Virginia, Charlottesville, VA, USA

${ }^{3}$ Division of Nephrology, Department of Medicine, University of Virginia, Charlottesville, VA, USA

Edited by:

Andrew P. Makrigiannis, University of

Ottawa, Canada

\section{Reviewed by:}

Dmitri V. Krysko, VIB, Belgium; Ghent

University, Belgium

Philippe Georgel, Strasbourg

University, France

*Correspondence:

Michael G. Brown, Department of Medicine, University of Virginia

School of Medicine, 345 Crispell

Drive, Charlottesville, VA 22908, USA

e-mail:mgbrown@virginia.edu
Natural killer (NK) cells provide essential protection against viral infections. One of the defining features of this lymphocyte population is the expression of a wide array of variable cell surface stimulatory and inhibitory NK receptors (sNKR and iNKR, respectively). The iNKR are particularly important in terms of NK-cell education. As receptors specific for $\mathrm{MHC}$ class I (MHC I) molecules, they are responsible for self-tolerance and adjusting NK-cell reactivity based on the expression level of self-MHC I. The end result of this education is twofold: (1) inhibitory signaling tunes the functional capacity of the NK cell, endowing greater potency with greater education, and (2) education on self allows the NK cell to detect aberrations in $\mathrm{MHC}$ I expression, a common occurrence during many viral infections. Many studies have indicated an important role for iNKR and $\mathrm{MHC} I$ in disease, making these receptors attractive targets for manipulating NK-cell reactivity in the clinic. A greater understanding of iNKR and their ability to regulate NK cells will provide a basis for future attempts at translating their potential utility into benefits for human health.

Keywords: NK cells, inhibitory receptors, virus control, immunity, education, licensing

\section{INTRODUCTION}

Natural killer (NK) cells are innate lymphocytes with broad specificity and a capacity for rapid recognition and activation. They participate in a wide variety of biological conditions spanning cancer, autoimmunity, pregnancy, and viral infections. Although originally identified and named for their ability to spontaneously lyse tumor cells $(1,2)$, clear evidence showcasing their importance comes from studies of virus control in the context of NK-cell deficiency. Human classical NK deficiency results in reduced numbers of NK cells, while functional NK deficiency results in normal NK-cell numbers but impaired responsiveness (3). Individuals exhibiting either of these conditions consistently present in the clinic with severe viral infections - especially herpesviruses $(3,4)$.

Unlike T and B cells, NK cells do not undergo DNA rearrangements to generate their cell surface receptors. Rather, they express a broad array of stimulatory and inhibitory NK receptors (NKR) encoded by genes clustered in the NK gene complex (NKC) and leukocyte receptor complex (LRC) (5-11). NK cells in both mice and humans express NKC-encoded C-type lectin-like receptors including NKG2D, NKG2A/C/E, and CD94. Mouse NK cells also express diverse Ly49 receptors, another NKC-encoded family of Ctype lectin-like receptors, whereas human NK cells express variable LRC-encoded killer Ig-like receptors (KIRs) (5-11).

The NKC and LRC represent two of the most variable and diverse genomic intervals, rivaling the MHC in terms of gene content $(7,9,12)$. Diversification of genomic intervals encoding NKR is evident in many species $(7,9)$ and is likely shaped by a variety of factors influencing fitness and survival, including pathogen resistance, detection of self-MHC I ligands, and reproductive success
(10). Two main points related to NKR variability require emphasis: (1) Independent convergent evolution of the NKR in many species highlights their functional importance; and (2) extensive intra- and inter-species NKR gene diversity is indicative of their instability and rapid evolution, likely due to balancing selection exerted by both MHC and pathogen genetics (9).

NK receptor expression in NK cells is variegated and can vary greatly from NK cell to NK cell. Interactions between NKR and their environment establish a balance of signals within the NK cell, favoring either tolerance or activation (12). Inhibitory (i)NKR specifically bind MHC class I molecules as ligands, allowing NK cells to patrol for normal self-MHC expression. Stimulatory (s)NKR bind to a variety of ligands including viral proteins and MHC I-related molecules induced by cellular stress pathways (1214). While roles for a number of sNKR in NK-mediated virus control have been established (15-17), the contributions of iNKR have been more difficult to unravel. Specific detection of viral or virus-induced host ligands by sNKR has been shown to enhance NK-cell activation, expansion, and viral clearance. However, a large body of work in the field also links iNKR activity to NK-cell target detection, sensitivity to sNKR stimulation, and capacity for effector function (cytokine production and target lysis). Thus, iNKR are likely to have prominent effects on immune responses, extending well beyond the disruption of activation signals and self-tolerance.

Here, we consider data concerning iNKR involvement in immunity. The discussion focuses on the importance of iNKR activity in a variety of processes including driving NK functional tuning, shaping viral evasion strategies, enhancing activation responses, and mediating specific recognition and control of viral infections. 


\section{INHIBITORY RECEPTORS INCREASE NK-CELL RESPONSIVENESS}

As mediators of NK-cell self-tolerance, iNKR safeguard against aberrant or chronic immune activation and the development of autoimmunity (18-24). However, iNKR signaling also leads to increased basal responsiveness in NK cells (25-30). Cognate interactions between iNKR and self-MHC I ligands tune the responsiveness of NK cells. This occurs through an educational process that has been referred to as "arming" or "licensing." When NK cells express an iNKR that can bind at least one self-MHC I ligand in their environment, they are said to be "licensed." These NK cells display increased ex vivo sensitivity to stimulatory receptor cross-linking compared to "unlicensed" NK cells lacking self-specific iNKR.

Two proposed models attempt to account for the differential responsiveness of NK cells stemming from the presence or absence of self-MHC binding iNKR. The "disarming" model contends that NK cells without any iNKR for self-MHC I are rendered hyporesponsive due to chronic low-level stimulation; whereas the "licensing" model predicts that NK cells without iNKR for selfMHC I simply fail to acquire full reactivity (Figure 1) $(26,31)$. Adherence to one or the other of these hypotheses may be too idealistic, though, as there is evidence to support both and they may indeed be occurring side-by-side in NK cells. Regardless of the mechanism, NK cells that sense self at steady state are more reactive to stimulation and changes in $\mathrm{MHC}$ class I expression than their self-ignorant counterparts.

Such iNKR licensing effectively bestows an added level of sensitivity to self-MHC ligand expression. NK tuning to normal levels of self-MHC expression broadens NK-cell specificity, allowing
licensed-NK cells to detect and respond against cellular targets failing to express adequate levels of self-ligand $(17,32,33)$. In short, productive licensing through inhibitory signaling provides a twofold benefit to NK function. It serves to simultaneously enhance effector responses (e.g., IFN $\gamma$ secretion and cytotoxicity) and broaden the NK-cell's target specificity to include aberrant cells that would not be detected by stimulatory receptors alone.

In light of these advantages, it is important to emphasize that licensing is a tunable process, i.e., that the extent of inhibitory receptor priming corresponds to the relative increase in NK-cell reactivity (34-36). Hence, the licensing effect is not a binary readout. Instead, it manifests as a rheostat determined by the total input from iNKR. Whether the enhancement of NK responsiveness is actively mediated by iNKR signals or simply the result of increased disruption of stimulatory NKR signaling is an important question that has yet to be resolved. Moreover, the licensing status of an NK cell is not fixed. Rather, several studies have shown that the responsiveness of NK cells can be reset after their transfer from one MHC I environment to another (37-39). These results suggest that the acquisition of functional reactivity is a dynamic process that results in continual NK-cell re-education.

While the mechanistic basis of NK-cell education is still unclear, it is known that the immunoreceptor tyrosine-based inhibitory motif (ITIM) in the iNKR cytoplasmic tail is required (29). Both mouse and human iNKR carry at least one ITIM that can bind cellular phosphatases containing Src homology 2 (SH2) domains. Phosphatase recruitment further leads to Vav dephosphorylation and the subsequent disruption of activation signals (Figure 1) (17). The role of SH2-containing phosphatases in NK-cell licensing and function has also been the subject of investigation $(40,41)$.

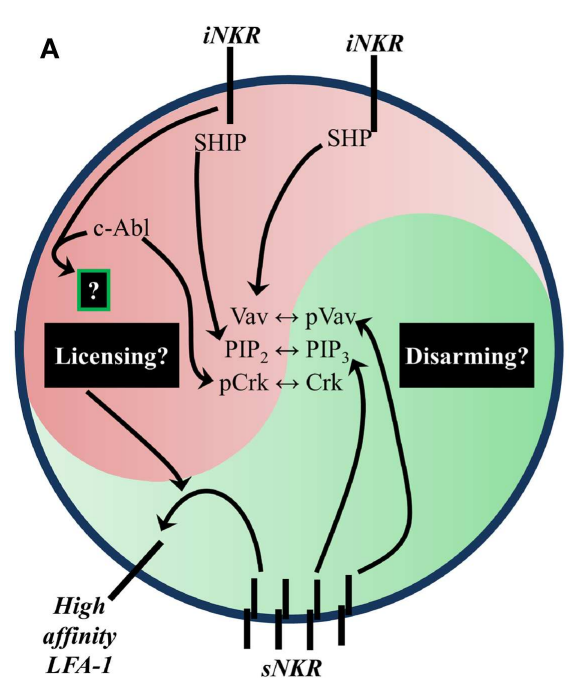

FIGURE 1 | Natural killer education primes NK cells for heightened effector function. (A) Inhibitory signaling serves a twofold purpose. On one hand, it can disrupt activation signals from sNKR at several intersections (e.g., SHP dephosphorylation of Vav, SHIP dephosphorylation of $\mathrm{PIP}_{3}$, and c-Abl sequestration of Crk from activation complexes). On the other hand, it also serves to tune the reactivity of the NK cell to activating stimuli, either through unknown positive signals transmitted downstream of iNKR ligation (licensing model) or prevention of anergy (disarming model). One distinct benefit of

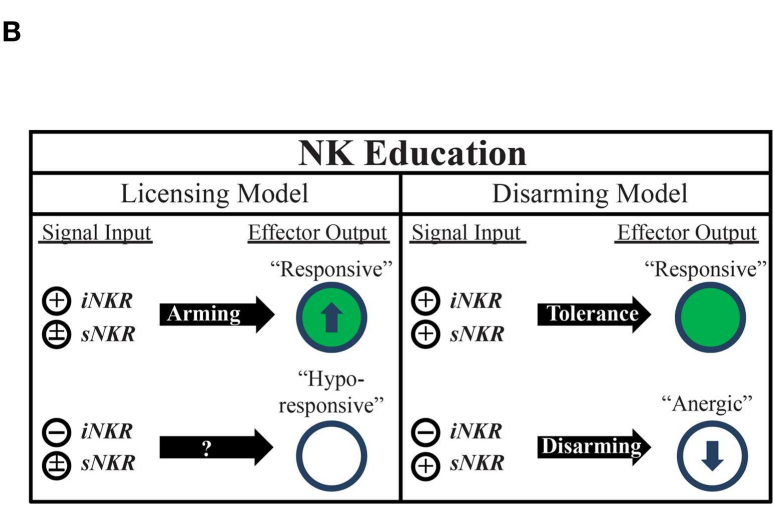

self-specific iNKR that has been recently established is the ability to enhance sNKR inside-out signaling to LFA-1 to promote adhesion and target recognition. (B) The balance of signals in NK cells determines their reactivity. NK that do not receive inhibitory signals can be activated in response to inflammatory stimuli and conditions, but are generally less responsive to sNKR stimulation (in terms of cytokine production and cytotoxicity) than NK that receive iNKR input. Whether this occurs via a licensing mechanism, disarming mechanism, or both is still not fully worked out. 
However, results from these studies have been difficult to interpret. The effects of SH2-containing tyrosine phosphatase 2 (SHP-2) on licensing are not well known due to the embryonic lethality of knockout mice (42). SH2-containing inositol phosphatase (SHIP) deficient mice exhibit skewed NKR repertoires with increased representation of certain iNKR (43). NK cells in these mice appear to have a defect in the enhancement of IFN $\gamma$ production but have intact missing-self recognition in response to reduced iNKR ligation $(43,44)$. SHP-1 has been studied in more detail than SHP-2 and is reported as the most prevalent phosphatase recruited to ITIMs during MHC-specific iNKR inhibition (25). In contrast with SHIP-/-, SHP-1 deficient mice had intact iNKR-mediated enhancement of IFN $\gamma$ but a markedly reduced ability to lyse targets with reduced or absent MHC I expression $(29,45)$. These results highlight the complexity of NK-cell education and may suggest that iNKR license NK cells via multiple, distinct pathways.

Indeed, there is now evidence for direct signaling events downstream from inhibitory receptors $(17,46,47)$. Rather than inducing complete broad-scale dephosphorylation, inhibitory receptor signaling also leads to specific phosphorylation of the small adaptor molecule, Crk (46). This results in its association with c-Abl and sequestration from activation signaling complexes (47). While it is still unknown if this leads to other downstream effects that may result from inhibitory receptor cross-linking, this discovery opens the possibility that inhibitory signaling could induce additional phosphorylation events that have yet to be identified (Figure 1).

Increased target cell adherence during conjugate formation is another positive effect of NK-cell education (48). Strong LFA1-dependent adhesion induces the formation of tight conjugates between NK cells and target cells $(49,50)$, as well as the subsequent polarization of lytic granules (51). Inside-out signaling from stimulatory receptors to LFA-1 causes it to shift into an open conformation, allowing for a stronger association with ICAM on target cells (52). Interestingly, cells educated via inhibitory signals were found to have enhanced activating receptor inside-out signaling (Figure 1). Following incubation with K562 target cells, activation signals in licensed-NK cells resulted in more high-affinity (open conformation) LFA-1 when compared to their unlicensed counterparts, which resulted in increased tight conjugate formation, lytic granule polarization, and target cell lysis (48). Thus, inhibitory tuning of NK cells potentiates increased responsiveness by enhancing sNKR signaling. Although the mechanistic basis of this effect on sNKR signaling is unknown, we can infer that iNKR signaling pathways exert a profound influence on the reactivity of licensed-NK cells.

Collectively, these studies provide substantial evidence of a critical role for iNKR signaling in the tuning of NK-cell function. While unlicensed-NK cells are capable effectors, education via iNKR provides NK cells with enhanced activation potential and an added layer of specificity for the detection of MHC class I fluctuations and/or aberrations. Such tuning is essential for the role of NK cells as sentinels of healthy self-gene expression.

\section{VIRAL EVASION TACTICS UNDERSCORE INIKR IMMUNE PRESSURE}

Evidence for the importance of NK-cell iNKR in viral resistance is seen in the immune evasion mechanisms employed by viruses.
Common viral strategies to avoid detection by CD8+ T cells involve the regulation of MHC I expression on the surface of infected cells. However, viruses must strike a balance between limiting MHC I presentation of virus-derived peptides and maintaining sufficient MHC I levels to prevent "missing-self" detection. Such manipulations have been described for many viruses, particularly those most susceptible to NK-mediated responses [Figure 2; reviewed in Ref. $(53,54)]$. While many viruses exploit iNKR as a way to evade immune detection, the targeted nature of these diverse strategies conveys the prominence of selective pressure exerted by NK cells and their iNKR.

\section{SELECTIVE MODULATION OF MHC I TO INHIBIT NK CELLS}

Human (H)CMV utilizes several immunoevasin proteins to selectively decrease MHC I expression on the surface of infected cells. Although seemingly redundant, the varied timing of expression, mechanisms of action, and allelic-specificities of these immunoevasins indicate a tightly orchestrated manipulation of class I expression responsible for HCMV's successful evasion of the

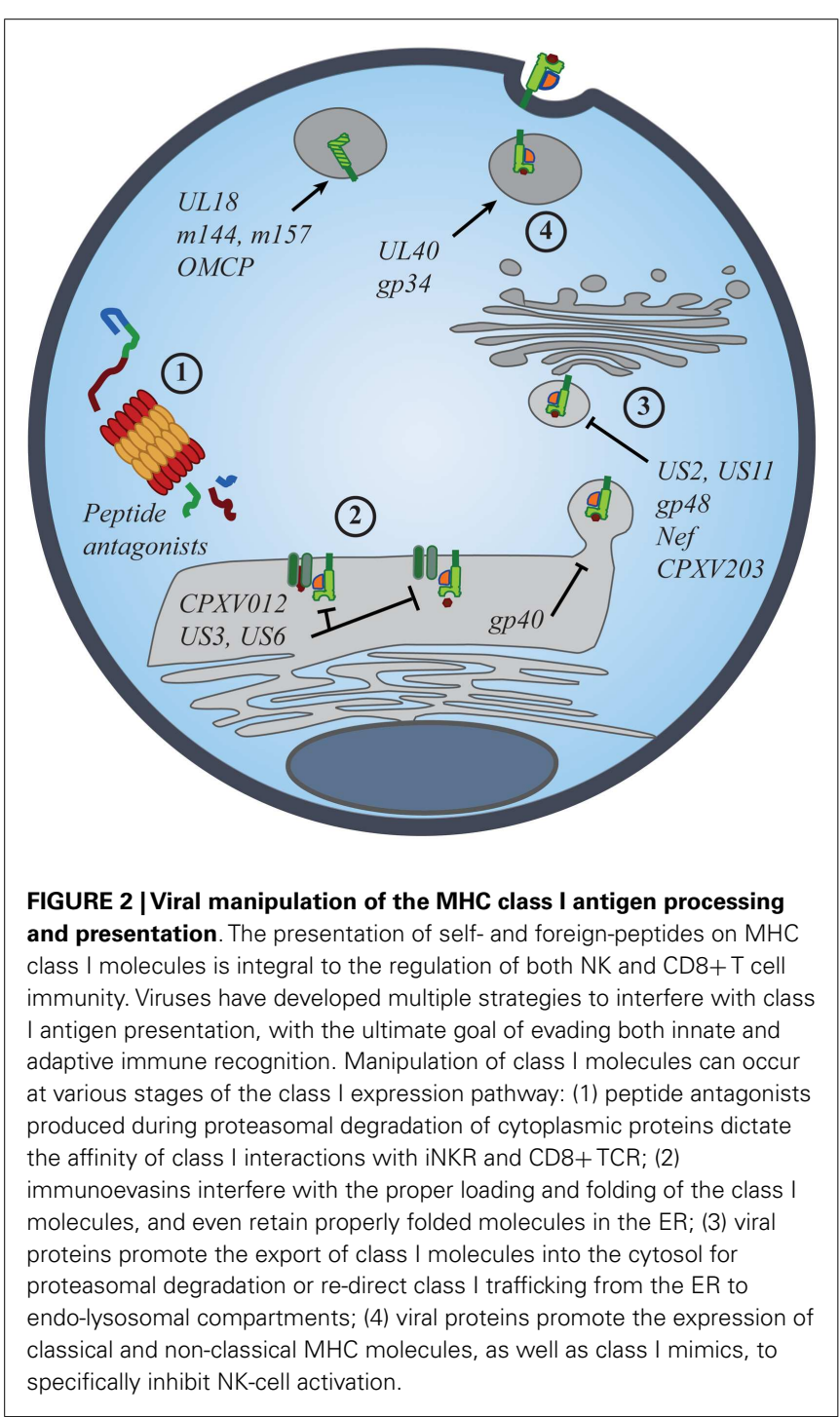


immune system. Both US3 and US6 retain MHC I in the ER. US3 interferes with tapasin-dependent peptide antigen transport (5557), whereas US6 binds to TAP and prevents the proper loading and folding of all MHC I $(58,59)$. As neither of these immunoevasins directly binds to specific class I alleles, their class I targets for downregulation are quite broad. US2 and US11, on the other hand, target and bind to specific, non-overlapping alleles of HLA-A and -B molecules for dislocation from the Golgi apparatus and subsequent degradation in the cytosol, leaving residual HLA$\mathrm{C}$ and -E expression to bind inhibitory KIR and NKG2A/CD94, respectively (59-61). Indeed, the non-overlapping specificities of these latter immunoevasins are indicative of the virus's acquired responses to the high degree of MHC I polymorphism (62). However, it is also possible that this arsenal of independent immunoevasins and their regulation was driven by iNKR. By encoding for non-redundant manipulators of class I expression, HCMV selectively regulates $\mathrm{MHC}$ surface expression in an attempt to protect itself from missing-self detection by NK cells.

Similar to HCMV, HIV-1 and cowpox virus (CPXV) downregulate surface expression of MHC I molecules to avoid lysis by CD8+ T cells. HIV Nef binds the cytoplasmic tails of HLA-A and -B molecules in the ER and then redirects them to endo-lysosomal compartments for degradation (63). Minor differences in the tails of HLA-C and -E prevent Nef from interfering with their trafficking to the cell surface, which in turn renders infected CD4+ T cells resistant to lysis by NK cells expressing the cognate inhibitory KIR (64-66). In cases where HLA-B is the cognate-ligand for inhibitory KIR, Nef-mediated downregulation of MHC I ligands may actually enhance NK-cell control of HIV-1 infection (discussed below) (67-69). However, pressures from self-licensed-NK cells may also select against Nef-mediated downregulation of HLA-B, as HLA$B$ appears to be more resistant to binding by certain Nef variants than HLA-A (70). CPXV proteins CPXV012 and CPXV203 diminish MHC I expression by blocking peptide transport into the ER and then interfering with MHC I trafficking in the Golgi (71-74). Further study is warranted to investigate how MHC I interference relates to HIV and CPXV evasion of NK-cell attack and the effect of host MHC polymorphism on $\mathrm{NK}$ and $\mathrm{T}$ cell recognition of virus-infected targets.

In addition to selective downregulation of allele-specific class I ligands, viruses also induce MHC I expression to inhibit NK cells. For example, a nonamer peptide derived from the leader sequence of HCMV UL40 that resembles the signal peptides of many HLA-C allotypes, binds to non-classical HLA-E in a TAPindependent manner $(75,76)$. This facilitates HLA-E export to the cell surface where it can engage the NKG2A/CD94 iNKR on NK cells. The promotion of inhibitory ligands by HCMV is beneficial and perhaps even necessary for immune evasion, as sequestration and degradation of classical MHC I molecules prevents the loading of signal peptides onto HLA-E, leaving the cell surface largely bare of MHC. However, increased expression of HLA-E can also render infected cells more susceptible to NK cells bearing the NKG2C/CD94 sNKR. A recent study of UL40 comparing clinical isolates of HCMV to the AD169 laboratory strain revealed increased polymorphism in the leader sequence mimic region from several isolates (77). While these polymorphisms had little impact on the ability of UL40-derived signal peptides to bind to and express HLA-E at the cell surface, non-conservative amino acid variations at specific positions were capable of abrogating NKG2C/CD94-mediated lysis while preserving inhibition through NKG2A/CD94.

Murine (M)CMV also encodes several glycoproteins that modify surface expression of MHC I molecules. MCMV gp40 sequesters loaded MHC I molecules in ER-Golgi intermediate compartments (78), whereas gp48 re-routes mature MHC I molecules to endo-lysosomal compartments for degradation (79). To balance this broad class I downregulation, MCMV gp34 binds and promotes MHC I expression at the cell surface (80-82). Indeed, these immunoevasins are both cooperative and antagonistic in function, and through a hierarchy of allele-specific binding, MCMV regulates surface MHC I expression to evade detection by NK cells and CD8+ T cells (83-85). Interestingly, gp34 mutations were found to accumulate over time in MCMV strains $(86,87)$, potentially allowing rapid adaptation of its MHC binding specificity. Thus, MCMV utilizes multiple strategies to fine-tune MHC I expression and evasion of iNKR + cells.

Viral microRNAs also have a role to play in evading the immune system (88). Interestingly, work so far on the subject seems to suggest a major role for these viral miRNAs in regulating the expression of certain ligands of the major sNKR NKG2D (89). For example, at least three separate herpesviruses have been shown to produce distinct miRNAs that all target the stress-inducible NKG2D ligand MICB. HCMV, Kaposi's sarcomaassociated herpesvirus (KSHV), and Epstein-Barr virus (EBV) all encode their own miRNA (miR-UL112, miR-K12-7, and miRBART2-5p, respectively) that bind adjacent regions of the MICB $3^{\prime}$ UTR and interfere with its translation and expression $(90,91)$. It is interesting to note that this mechanism of NK evasion favors reduced sNKR recognition over increased iNKR inhibition; so there is not necessarily a direct impact on iNKR signaling. This shows that viruses exploit the internal regulation of NK cells (i.e., the "balance of signals") either by increasing inhibition or reducing stimulation to escape NK detection. It is tempting to speculate here that a licensed NK may have an advantage in the face of MICB downregulation since they are more sensitive to activation stimuli, however this has not yet been explored.

\section{EVASION OF NK CELLS THOUGH MOLECULAR MIMICRY}

On top of selective editing of the class I repertoire, viruses use MHC I-related protein mimics that directly interfere with NK cells. The HCMV glycoprotein UL18, for example, binds to the iNKR ILT2/LIR-1 to interfere with LIR1+ NK-cell mediated cytotoxicity (92). For LIR1+ NK cells, the degree of UL18-mediated inhibition was directly related to the amount of LIR-1 available on the NK-cell surface. Interestingly, while highly protective against LIR1+ cells on a clonal level, UL18 + target cells actually increased the cytotoxicity of LIR1- NK cells through LIR-1-independent mechanisms. In a polyclonal population of NK cells, this increased cytotoxicity of LIR-1-cells was generally sufficient to mask the inhibition afforded by UL18. CPXV OMCP is another MHC Irelated molecule that may interfere with NK cells by antagonizing NKG2D-mediated NK-cell stimulation (93). In MCMV, m144 fulfills an orthologous mechanism of NK-cell inhibition, mimicking key structural features of the H-2 molecule (94-96). Although 
its cognate receptor is unknown, both functional and biochemical studies implicate m144 as a key regulator of mouse NK cells (94, 95, 97). Interestingly, UL18 and m144 share more sequence and structure similarities with MHC I molecules than they do with each other, suggesting that convergent evolution led to the independent acquisition of MHC I mimics due to species-specific immune pressure $(96,97)$ in a way reminiscent of the convergent evolution of iNKR among species.

MCMV m157 is another MHC I-related molecule that may have specifically evolved to engage NK-cell iNKR (98-100). Distinct variations in its three-dimensional folds and the lack of association with $\beta 2$-microglobulin enables $\mathrm{m} 157$ to interact with iNKR with greater affinity than their cognate MHC I ligands $(101,102)$. Discovery of the inhibitory nature of m157 was made after the initial observations between enhanced viral control and Ly49H stimulatory receptor recognition of $\operatorname{ml} 157$ (98, 99, 103106). Despite its dominant activating properties in C57BL/6 (B6) mice and strains bearing $\mathrm{Ly}_{49 \mathrm{H}^{\mathrm{b} 6}}$, it was hypothesized that $\mathrm{m} 157$ initially evolved to inhibit NK cells in the wake of broad downregulations of endogenous MHC I molecules, similar to m144. Indeed, the MCMV-susceptible 129/J allele of the iNKR Ly49I shares substantial sequence similarity with Ly49H ${ }^{\text {b6 }}$ (107). Moreover, Ly49I ${ }^{129}$ binds to m157-Ig fusion proteins (99) and may even possess a higher affinity for $\mathrm{m} 157$ than $\mathrm{Ly} 49 \mathrm{H}^{\mathrm{b} 6}$ (101). Despite the limitations of fully resolving the inhibitory effects of m157 on Ly49I ${ }^{129}$ in vivo, it was demonstrated that $129 / \mathrm{J}$ mice infected with $\Delta \mathrm{m} 157$ virus exhibited limited, but significant, reductions in viral titers compared to WT BAC-MCMV-infected mice (103). Further support for m157's immune evasive role can be gleaned from the work of Scalzo and colleagues who found that m157 variants isolated from wild outbred mice bind an array of inhibitory Ly 49 with a wide range of affinities while very few of them activate Ly49H (100).

It is important to note that infection and immunity are inextricably linked in an evolutionary arms race $(10,108,109)$. While immune surveillance mechanisms represent important targets, successful viral evasion strategies can paradoxically become triggers for immune stimulation. Importantly, scientific findings from models investigating viral evasion and immunity are inherently based on a fixed point in evolution. Although viruses rapidly evolve to evade NK-cell detection, the immune system of a population is also constantly evolving to overcome these hurdles (110).

This observed co-evolution has been independently substantiated by de Boer and colleagues through in silico modeling. Using a simplified model of human KIR diversity and a herpesvirus-like agent that could downregulate or promote the expression of decoy MHC I molecules, they demonstrated that viral evasion strategies invariably informed the degree of KIR specificity for HLA, and that the existence of decoy models necessitated by a diverse KIR repertoire to distinguish host ligands from decoys (111). The fact that highly variable and rapidly evolving regions of the genome encode so many iNKR strongly indicates their importance in combating viral infections that are also continually adapting to their hosts.

\section{EVIDENCE FOR LICENSED-NK-MEDIATED VIRAL CONTROL}

Many sNKR (e.g., Ly49H and NKp46) have been shown to specifically bind proteins expressed by certain viruses including herpesviruses, influenza, and poxviruses (98, 99, 104, 112-115). This allows NK cells to specifically recognize and eliminate viral pathogens. As an example, human XMEN deficiency, which results in an $\mathrm{Mg} 2+$ defect and poor NKG2D expression on NK cells, was overcome with $\mathrm{Mg} 2+$ supplementation that led to increased NKG2D expression and enhanced EBV clearance (116). NKG2C is another sNKR frequently expressed by NK-cell subsets. NKG2C+ NK cells preferentially expand after exposure to HCMV (117), potentially indicating specific activation in response to the infection.

Since iNKR bind highly polymorphic MHC I ligands and prevent the lysis of normal, healthy cells, viral modulation of $\mathrm{MHC}$ I molecules resulting in a loss of self-MHC elicits iNKR release and lysis of infected cells. While this general recognition mechanism is well established, the contribution of iNKR to specific recognition and clearance of viral infections is less clear. A growing body of literature now documents that iNKR + NK cells also expand and acquire greater reactivity after viral exposure, which raises additional questions: Is NK-cell subset expansion necessarily linked with specific recognition and lysis of infected target cells? What mechanism(s) can explain increased responsiveness of self-licensed iNKR + NK cells? Can licensed-NK cells recognize and respond to viral infection in the face of viral evasion? Does a licensed-NK-mediated response to viral infection result in NKcell memory? These and other important questions are presently unanswered and provide the framework for further review of data alluding to the critical role of licensed-NK cells in viral defense.

\section{EXPANSION OF INKR+ NK CELLS IN RESPONSE TO VIRAL INFECTION}

Previous studies have documented that certain iNKR + NK-cell subsets consistently expand after viral exposure $(105,118)$. Several scenarios may account for this. First, iNKR+ NK subset expansion may be related to non-specific effects associated with broad immune activation or inflammation. Expression of NKR is variegated, but unequal within the NK compartment. Thus, certain highly represented iNKR may simply have an expression advantage and will be primed to expand during NK proliferation. Alternatively, accumulation of iNKR + NK cells could result from co-expression with an unknown NKR that is required for the specific recognition of and response to infection, essentially making it a biomarker of expansion. Lastly, a given iNKR+ NK subset may increase as the result of the iNKR itself specifically detecting and responding to an infection. Expansion due to specific recognition has been shown for the stimulatory $\mathrm{Ly} 49 \mathrm{H}$ receptor and specific recognition by a licensed-NK cell could result in a similar outcome. Importantly, these possibilities are not mutually exclusive, and NK-cell expansion could result from multiple, simultaneous mechanisms.

In B6 mice, expansion of the iNKR Ly49G2+ $(\mathrm{G} 2+)$ NK-cell subset is a common observation. This $\mathrm{G} 2+\mathrm{NK}$-cell expansion appears to occur non-specifically in response to a wide spectrum of conditions, including diverse viral and bacterial infections, sterile stimulation of the immune system, and hematopoietic stem cell transplant (HSCT) $(119,120)$. However, this is unlikely to be a general feature of iNKR since a propensity for expansion has not been observed with any other inhibitory Ly49+ NK subset. Rather, selective $\mathrm{G} 2^{\mathrm{b} 6}$ allelic regulation or epistatic interactions 
could affect its expression in NK cells. This is supported by studies showing $\mathrm{G} 2^{\text {balb }}+\mathrm{NK}$ cells failed to similarly expand after poly I:C treatment or MCMV infection $(85,119,121)$. Even in F1 mice expressing both $\mathrm{G} 2^{\mathrm{b} 6}$ and $\mathrm{G} 2^{\text {balb }}$ receptors, $\mathrm{G} 2^{\mathrm{b} 6}+\mathrm{NK}$ cells expanded to a greater degree when directly compared to $\mathrm{G} 2{ }^{\mathrm{balb}}+$ NK cells (119). Further study is needed to clarify the role of $\mathrm{G} 2^{\mathrm{b} 6}+$ NK cells in response to conditions that elicit NK-cell expansion and what this propensity for expansion may mean.

On the other hand, G2 ${ }^{\text {c57l }}+\mathrm{NK}$ cells were found to selectively expand and control MCMV infection in the presence of the self-MHC I ligand $\mathrm{D}^{\mathrm{k}}$. The proportion of G2+ NK cells reliably increases in response to MCMV infection when $D^{k}$ is expressed. However selective increases in G2+ cell number have been most evident in mice given relatively high dose MCMV infection (122). This suggests that the $\mathrm{G} 2^{\mathrm{c571}}+\mathrm{NK}$ cells are uniquely reactive against MCMV targets and, as a result, preferentially accumulate. Extensive genetic analysis has shown that G2+ NK-mediated viral control is evident over a large range of infectious MCMV doses and it is always highly correlated with expression of the self-ligand $D^{k}$ $(123,124)$. That the increase in NK-cell numbers is dose dependent further supports that this is a specific response to MCMV infection. Two major questions requiring further study arise from these observations: (1) Is the licensed-NK response against MCMV dependent on a threshold level of viral infection? and (2) Does the licensed-NK response cooperate with sNKR (e.g., Ly49P and/or NKG2D) recognition of key targets to mount the observed NK-cell expansion?

Human studies have documented expansion of NK subsets marked by combinations of sNKR and self-specific inhibitory KIR (e.g., NKG2C and iKIR) (16). This feature is prominent in HCMV infection (117, 125-131), but may also occur in hantavirus (132), chikungunya virus (133), HIV-1 (125, 126, 134), and hepatitis infections (135). Unfortunately, extensive co-infection has made it difficult to resolve if the observed NK-cell expansion associated with the latter four is HCMV-dependent. However, a study on EBV and CMV co-infection showed that while all CMV seropositive children had increased NKG2C+ NK cells, the amount of NKG2C skewing was even greater in patients that were CMV/EBV double-seropositive (136). While still inconclusive, this could suggest that the co-infection can increase the NKG2C representation either by providing additional, non-specific effects from EBV infection or that the CMV-experienced NKG2C+ NK may specifically respond to the EBV infection. An important issue to be addressed is whether the self-licensed KIR on the expanded cells are simply endowing the NKG2C+ cells with an enhanced ability to expand or are explicitly contributing to specific viral recognition and $\mathrm{NK}$ activation. Additionally, these NKG2C+ cells have been described by some as memory NK (128), which presents the intriguing possibility that iNKR could mark memory NK.

A study by Alter et al. (137) has also reported that KIR3DS1+ and KIR3DL1 + NK cells expand in peripheral blood during HIV infection. However, in related work, only the KIR3DS1+ cells were observed to expand (138). Nonetheless, the expansion depended on the presence of KIR3DL1, and individuals with two copies of KIR3DL1 exhibited a clear enhancement in KIR3DS1 expansion over those with one copy. While this undoubtedly indicates a role for the iNKR, its relationship with the stimulatory receptor is still unclear.

\section{SPECIFIC INKR RESPONSES TO VIRAL INFECTIONS}

It was the pioneering work of Scalzo and Shellam, studying genetic control of the host response to MCMV, which led ultimately to the discovery of $\mathrm{Ly} 49 \mathrm{H}$ - a major MCMV resistance factor expressed in B6 mice (139). Ly49H binding to MCMV m157 was shown to increase NK-cell proliferation and direct lysis of MCMV-infected target cells $(98,99,140)$. Scalzo's studies further revealed that the B6-related MA/My mouse strain also relies on NK cells to mediate MCMV resistance (141). This result prompted extensive genetic screening for additional host genetic factors that protect against viral infection.

We have used classical genetics approaches to analyze the offspring obtained by crossing MA/My with C57L (MCMV susceptible), another B6-related mouse strain. Because the NKC-Ly49 haplotype common to both strains differs from B6 (142), it was reasoned that either a minor NKR polymorphism or an NKCindependent effect produced the difference in viral control. Using a parallel genetics screen, Vidal and coworkers compared MA/My with the BALB (also MCMV susceptible) mouse strain (143). Both genetic approaches mapped a critical interval centered on the gene coding for MHC I D $(122,143,144)$. Its role in MCMV resistance was verified in $\mathrm{C} 57 \mathrm{~L}$-derived transgenic $\mathrm{D}^{\mathrm{k}}$ mice and in FVBderived (also MCMV susceptible) class I null mice $(123,145)$. Together these studies demonstrated that MHC and non-MHC genetic factors regulate NK-mediated MCMV resistance and that the MHC I D ${ }^{\mathrm{k}}$ molecule itself has a major effect on viral control.

MHC I $\mathrm{D}^{\mathrm{k}}$ expression was expected to correspond with enhanced MCMV target detection and lysis via a sNKR, analogous to $\mathrm{Ly} 49 \mathrm{H}+$ control in B6 mice. Ly49P was proposed to mediate MCMV control based on genetic analysis of the resistance phenotype and its recognition of MCMV-gp34-associated $D^{k}$ molecules on infected cells $(113,143)$. However, its role has been difficult to verify in vivo without monospecific mAbs for detection and immunodepletion of Ly49P + NK cells. NKG2D + NK cells could also contribute to $\mathrm{D}^{\mathrm{k}}$-mediated MCMV resistance (85). Despite these possibilities, we found that $\mathrm{D}^{\mathrm{k}}$-mediated MCMV resistance in MA/My and C57L-derived $\mathrm{D}^{\mathrm{k}}+$ mice was abrogated by specific immunodepletion of G2+ NK cells. Diminished virus control due to G2+ NK-cell deficiency was observed after treatment with either of two different G2-specific mAbs, which verifies the crucial role of the subset in viral detection and clearance $(122,123)$.

However, iNKR signaling might also interfere with sNKR activation and viral control. This was examined in neonatal B6 mice adoptively transferred with adult NK cells. MCMV-specific $\mathrm{Ly} 49 \mathrm{H}+(\mathrm{H}+) \mathrm{NK}$ cells sorted into self-licensed Ly49C/I+ and unlicensed Ly49C/I- NK subsets were assessed for their ability to confer viral control (146). Despite the fact that all $\mathrm{H}+$ cells became activated after MCMV exposure, the unlicensed-NK cells exhibited more effective viral control (146). These data demonstrated that unlicensed-NK cells could have a dominant role in viral clearance, particularly when viruses successfully escape licensed-NK cells.

Although MCMV evaded and perhaps even exploited selflicensed-NK-cell detection in the above B6 mice, differences in the different models of NK-mediated viral immunity suggest that 
licensed-NK-mediated viral control may depend on specific recognition of virus-infected targets via altered MHC I sensing. This question was further tested in a large-scale genetic analysis of the host response to MCMV (124). More than 200 mice disparate for the $\mathrm{G} 2^{\mathrm{c} 571}$ cognate-ligand, $\mathrm{D}^{\mathrm{k}}$, were analyzed for immune and $\mathrm{NK}$-cell features in the response to infection, in parallel with viral control. Remarkably, the results demonstrated that G2 expression on NK cells, the percentage of G2+ NK cells before infection and their expansion afterward, in addition to MCMV resistance, were all linked to the presence of $\mathrm{D}^{\mathrm{k}}$ in the genome. We infer from these results that self- $\mathrm{D}^{\mathrm{k}}$-licensed-NK cells were effectively poised to efficiently recognize and respond to targets, which led to more effective sNKR signaling, lysis of infected cells, and viral control.

The results above predict that licensed-NK cells may also contribute viral control in B6 mice, as long as one or more iNKR adequately recognize altered expression of a key self-ligand. In agreement with this, Murphy and colleagues reported that licensed-NK cells selectively expanded following MCMV exposure in syngeneic HSCT recipients, which corresponded to increased viral control (147). A similar result was observed in allo-HSCT recipients, which implies that licensed-NK cells were generally more responsive to MCMV in transplanted recipients (148). An intriguing possibility is that a licensed-NK response to MCMV is actively suppressed by regulatory T cells and TGF $\beta$ in $\mathrm{B} 6$ mice, but becomes measurable after HSCT and in $\mathrm{T}_{\text {reg- }}$ or TGF $\beta$-depleted mice (147). Though this seems inconsistent with MCMV gp34-mediated interference with iNKR detection, it may be possible that gp34 stabilization of critical self-ligands is less effective in the setting of HSCT. Indeed, NK-cell reactivity is sensitive to MHC I expression after HSCT $(149,150)$, and the functional reactivity of licensed-NK cells in HSCT patients was found to be responsive to self-ligand expression on donor-derived hematopoietic cells (i.e., NK are functionally licensed on transplanted donor cells following HSCT) (151). Further work is needed to fully understand the genetic and environmental impacts on NK-cell licensing and reactivity and how these influence NK behavior during infection.

Human studies also provide evidence that individuals with a given configuration of matched iNKR:HLA class I may exhibit enhanced viral control. Correlations between matched inhibitory KIR and HLA have been observed in responses to HIV-1 (3DL1:HLA-Bw4), HCV (2DL3:HLA-C1), influenza (3DL1:HLA-Bw4; 2DL2/DL3:HLA-C1), and vaccinia virus (VV) (NKG2A:HLA-E) [(152); reviewed in Ref. $(16,153)]$. These associations provide evidence for a direct contribution of iNKR and licensed-NK cells to virus control.

As discussed above, 3DL1/S1 + NK cells can expand during HIV-1 infection. This expansion is dependent on the expression of the cognate-ligand for these KIR in the individual (HLA-Bw4-80I) (137, 138). Individuals who express this particular HLA exhibit better control of HIV viremia as well as significant protection from developing AIDS (67). In a group of controllers expressing the 3DL1:HLA-Bw4 pair, protection was more strongly associated with high NK-cell activity than CD8 T cell responses (69). HIV-1 peptide antagonism, in part, may account for these observations: the HLA-Bw4 restricted immunodominant Gag240-249 TW10 T cell epitope is targeted by CD8 + T cell effectors early after infection. HIV-1 variants of the TW10 epitope, while successful at evading CD8 $+\mathrm{T}$ cells, often interfere with 3DL1 binding to its cognate-ligand and thereby potentially render infected cells more susceptible to "missing-self" detection by NK cells (154). In addition, expression of increasing levels of strongly inhibitory 3DL1 in conjunction with its ligand enhances the observed protective effect of this iNKR, further strengthening the link between this KIR:HLA pair and HIV control (68).

Genetics studies have also indicated a potential role for HLA-C (alleles of which can serve as ligands for 2DL1, 2DL2, and 2DL3) expression in HIV control, but the importance of NK cells and KIR:HLA pairing in this observation is still uncertain (155-160). Some work has indicated that 2DL2 exerts significant pressure on HIV. Individuals with this iNKR have a prevalence of HIVpolymorphisms in a region spanning the $\mathrm{Vpu}$ and Env proteins. These polymorphisms allow binding of 2DL2 upon HLA-C presentation whereas the HIV wild type sequences do not (161). In a related study screening 217 different Gag peptide sequences, only 11 were found to stabilize HLA-Cw-0102, and of those 11, only one of these could mediate inhibition of 2DL2 expressing NK cells (162). These studies suggest that, even though HLA-C is not modulated by Nef on the surface of infected cells, many HIV peptides are inefficient at inhibiting 2DL2 + NK cells, pressuring the virus to rely on peptide diversification during infection of individuals with 2DL2.

Natural killer cells are generally activated in response to HCV infection (when compared with NK from uninfected controls), but NK cells positive for 2DL2/L3 tended to exhibit increased degranulation in response to K562 targets; particularly in cases of self-limited infection (163). Individuals homozygous for the 2DL3:HLA-C1 pair exhibit enhanced control of the virus following low-dose exposure and this partnership is also associated with spontaneous clearance of the infection $(164,165)$. In addition, the homozygous genotype is correlated with apparent resistance to infection in i.v. drug users (prolonged seronegativity despite continual exposure) and positive responses to treatment after $\mathrm{HCV}$ infection (166).

In a model of human influenza A virus (IAV) infection, NK cells from subjects homozygous for 2DL3 and HLA-C1 were more reactive to IAV infected cells than those from individuals homozygous for the 2DL1:HLA-C2 ligand pair (167). Another study looked at the influence of 3DL1, 2DL1, and 2DL2/3 in H1N1/09 infected ICU patients (2009 pandemic IAV strain). The results showed that individuals expressing all three iNKR had the lowest risk of death and that ICU patients exhibited decreased ligation of 3DL1/S1 by HLA-Bw4 and 2DL1 by HLA-C2 (168), suggesting that stronger interactions between these KIR:HLA pairs may be protective on some level.

While the human NK response to $\mathrm{VV}$ infection appears to involve NK cells to some degree, the role of iNKR:HLA has not been rigorously studied. However, an in vitro investigation using an autologous cell system showed differences in VV reactivity among NK subsets from an individual subject. NK cells expressing high levels of NKG2A were far more efficient at lysing VV infected cells than their $2 \mathrm{DL} 1+$ or $\mathrm{NKG}_{2} \mathrm{~A}^{\mathrm{dim}}$ counterparts (152). This increased lysis was abrogated by rescuing HLA-E expression on target cells, indicating the activity was due to NKG2A-mediated detection of reduced HLA-E. 
Several possibilities could account for the apparent benefits of these genetic pairings: (1) KIR:HLA pairings may correspond with more effective NK-mediated viral control. Early control of viral replication and/or less severe inflammation may correspond to less morbidity and mortality over time. (2) Genetic pairings favoring NKR and HLA could affect NK-mediated regulation of adaptive immune responses. More efficient priming of T cells and less interference with $\mathrm{T}$ cell mediated immunity could substantially augment viral control and clearance. (3) Genetic pairings might affect other immune cell features (e.g., DC numbers and/or costimulatory molecule expression) that have the potential to affect $\mathrm{NK}$ cells and/or T cells needed to further control viral infection and replication. (4) Licensed-NK cells may regulate other types of NK cells, including unlicensed-NK cells, to mount a more vigorous attack against infected targets. We speculate that iNKR-mediated sensing of viral targets can enhance the responsiveness of NK cells to stimulatory receptor signaling and augment their capacity to lyse infected targets. It will be important to rigorously investigate these possibilities in the future and identify the mechanisms through which iNKR-licensed-NK cells can augment immunity and virus control (Figure 3).

\section{CLOSING REMARIKS}

Important insight into the benefits of iNKR-mediated enhancement of NK-cell reactivity has been gleaned from analyzing NKcell responses during viral infection. It is known that iNKR tune NK cells to efficiently detect and lyse target cells that lack selfMHC I expression, including virus-infected cells. Viral immune

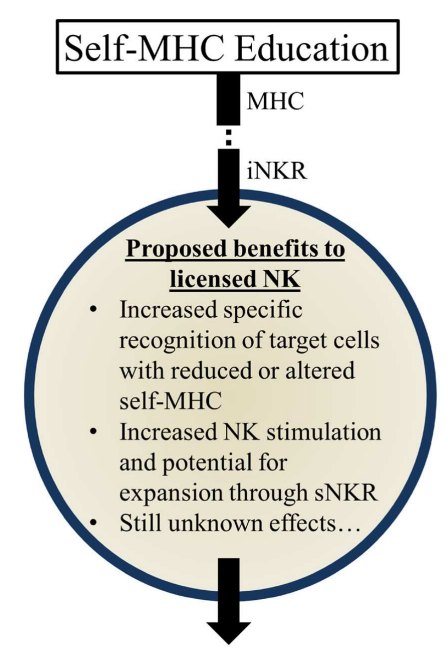

Potential benefits to host immunity

- Increased survival and /or costimulatory capability of DC

- Efficient T cell priming and/or memory

- Enhanced general NK response regulated by licensed NK

- Increased viral clearance, reduced inflammation and tissue pathology

FIGURE 3 | Summary of proposed beneficial effects of licensed-NK cells. NK Licensing potentially impacts the immune response in a variety of ways. Benefits may manifest directly as NK specific recognition or indirectly via effects on their environment and other cells. evasion strategies that target iNKR+ NK cells lend credence to their importance in defending against viral infection. The value of iNKR in immunity and survival is also evidenced by their "conserved diversity." This trait is reminiscent of MHC polymorphism shaped by co-evolution with diverse pathogens. It is clear that NKcell responses are intimately tied to the expression and diversity of iNKR and MHC I. Ultimately, the receptor-ligand interactions between these two protein families can shape NK-mediated immunity, host protection, and evolutionary success. Further study of iNKR in viral immunity should yield better understanding of NKcell education and its functional role in viral resistance. Learning more about iNKR and the regulation of NK cells should also help in realizing their potential for clinical applications in chronic infection, transplantation, tumor immune therapy, and/or immune deficiency.

\section{ACKNOWLEDGMENTS}

This work was supported by NIH grants (to Michael G. Brown) AI050072, AI082024, and AI083024. We thank all past and present lab members for their significant contributions to the research. We also thank Ebony Coats for helpful discussion and comments on the manuscript.

\section{REFERENCES}

1. Herberman RB, Nunn ME, Lavrin DH. Natural cytotoxic reactivity of mouse lymphoid cells against syngeneic and allogeneic tumors. I. Distribution of reactivity and specificity. Int J Cancer (1975) 16:216-29. doi:10.1002/ijc. 2910160205

2. Kärre K. Natural killer cell recognition of missing self. Nat Immunol (2008) 9:477-80. doi:10.1038/ni0508-477

3. Orange JS. Unraveling human natural killer cell deficiency. J Clin Invest (2012) 122:798-801. doi:10.1172/JCI62620

4. Orange JS. Natural killer cell deficiency. J Allergy Clin Immunol (2013) 132:515-25. doi:10.1016/j.jaci.2013.07.020

5. Martin AM, Kulski JK, Witt C, Pontarotti P, Christiansen FT. Leukocyte Ig-like receptor complex (LRC) in mice and men. Trends Immunol (2002) 23:81-8. doi:10.1016/S1471-4906(01)02155-X

6. Yokoyama WM, Plougastel BFM. Immune functions encoded by the natural killer gene complex. Nat Rev Immunol (2003) 3:304-16. doi:10.1038/nri1055

7. Kelley J, Walter L, Trowsdale J. Comparative genomics of natural killer cell receptor gene clusters. PLoS Genet (2005) 1:129-39. doi:10.1371/journal.pgen. 0010027

8. Carlyle JR, Mesci A, Fine JH, Chen P, Bélanger S, Tai LH, et al. Evolution of the Ly49 and Nkrp1 recognition systems. Semin Immunol (2008) 20:321-30. doi:10.1016/j.smim.2008.05.004

9. Yoder JA, Litman GW. The phylogenetic origins of natural killer receptors and recognition: relationships, possibilities, and realities. Immunogenetics (2011) 63:123-41. doi:10.1007/s00251-010-0506-4

10. Parham P, Moffett A. Variable NK cell receptors and their MHC class I ligands in immunity, reproduction and human evolution. Nat Rev Immunol (2013) 13:133-44. doi:10.1038/nri3370

11. Moussa P, Marton J, Vidal SM, Fodil-Cornu N. Genetic dissection of NK cell responses. Front Immunol (2013) 3:425. doi:10.3389/fimmu.2012.00425

12. Vivier E, Raulet DH, Moretta A, Caligiuri MA, Zitvogel L, Lanier LL, et al. Innate or adaptive immunity? The example of natural killer cells. Science (2011) 331:44-9. doi:10.1126/science.1198687

13. Lanier LL. NK cell recognition. Annu Rev Immunol (2005) 23:225-74. doi:10. 1146/annurev.immunol.23.021704.115526

14. Raulet DH, Gasser S, Gowen BG, Deng W, Jung H. Regulation of ligands for the NKG2D activating receptor. Annu Rev Immunol (2013) 31:413-41. doi:10.1146/annurev-immunol-032712-095951

15. Koch J, Steinle A, Watzl C, Mandelboim O. Activating natural cytotoxicity receptors of natural killer cells in cancer and infection. Trends Immunol (2013) 34:182-91. doi:10.1016/j.it.2013.01.003 
16. Jost S, Altfeld M. Control of human viral infections by natural killer cells. Annu Rev Immunol (2013) 31:163-94. doi:10.1146/annurev-immunol032712-100001

17. Long EO, Sik Kim H, Liu D, Peterson ME, Rajagopalan S. Controlling natural killer cell responses: integration of signals for activation and inhibition. Annu Rev Immunol (2013) 31:227-58. doi:10.1146/annurev-immunol020711-075005

18. Zimmer J, Donato L, Hanau D, Cazenave JP, Tongio MM, Moretta A, et al. Activity and phenotype of natural killer cells in peptide transporter (TAP)-deficient patients (type I bare lymphocyte syndrome). J Exp Med (1998) 187:117-22. doi:10.1084/jem.187.1.117

19. Gadola SD, Moins-Teisserenc HT, Trowsdale J, Gross WL, Cerundolo V. TAP deficiency syndrome. Clin Exp Immunol (2000) 121:173-8. doi:10.1046/j.13652249.2000.01264.x

20. Arkwright PD, Abinun M, Cant AJ. Autoimmunity in human primary immunodeficiency diseases. Blood (2002) 99:2694-702. doi:10.1182/blood. V99.8.2694

21. Zimmer J, Andrès E, Donato L, Hanau D, Hentges F, de la Salle H. Clinical and immunological aspects of HLA class I deficiency. QJM (2005) 98:719-27. doi:10.1093/qjimed/hci112

22. Villa-Forte A, de la Salle H, Fricker D, Hentges F, Zimmer J. HLA class I deficiency syndrome mimicking Wegener's granulomatosis. Arthritis Rheum (2008) 58:2579-82. doi:10.1002/art.23675

23. Caversaccio M, Bonél H, Carter R, Williams A, Gadola S. TAP deficiency syndrome: chronic rhinosinusitis and conductive hearing loss. Eur Arch Otorhinolaryngol (2008) 265:1289-92. doi:10.1007/s00405-008-0610-3

24. Bashirova AA, Martin MP, McVicar DW, Carrington M. The killer immunoglobulin-like receptor gene cluster: tuning the genome for defense. Annu Rev Genomics Hum Genet (2006) 7:277-300. doi:10.1146/annurev. genom.7.080505.115726

25. Joncker NT, Raulet DH. Regulation of NK cell responsiveness to achieve selftolerance and maximal responses to diseased target cells. Immunol Rev (2008) 224:85-97. doi:10.1111/j.1600-065X.2008.00658.x

26. Elliott JM, Yokoyama WM. Unifying concepts of MHC-dependent natural killer cell education. Trends Immunol (2011) 32:364-72. doi:10.1016/j.it.2011. 06.001

27. Lowin-Kropf B, Held W. Positive impact of inhibitory Ly49 receptor-MHC class I interaction on NK cell development. J Immunol (2000) 165:91-5.

28. Fernandez NC, Treiner E, Vance RE, Jamieson AM, Lemieux S, Raulet DH. A subset of natural killer cells achieves self-tolerance without expressing inhibitory receptors specific for self-MHC molecules. Blood (2005) 105:4416-23. doi:10.1182/blood-2004-08-3156

29. Kim S, Poursine-Laurent J, Truscott SM, Lybarger L, Song YJ, Yang L, et al. Licensing of natural killer cells by host major histocompatibility complex class I molecules. Nature (2005) 436:709-13. doi:10.1038/nature03847

30. Held W. Tolerance and reactivity of NK cells: two sides of the same coin? Eur J Immunol (2008) 38:2930-3. doi:10.1002/eji.200838755

31. Raulet DH, Vance RE. Self-tolerance of natural killer cells. Nat Rev Immunol (2006) 6:520-31. doi:10.1038/nri1863

32. Ljunggren HG, Kärre K. In search of the 'missing self': MHC molecules and NK cell recognition. Immunol Today (1990) 11:237-44. doi:10.1016/14714906(90)90097-H

33. Raulet DH. Missing self recognition and self tolerance of natural killer (NK) cells. Semin Immunol (2006) 18:145-50. doi:10.1016/j.smim.2006.03.003

34. Brodin P, Kärre K, Höglund P. NK cell education: not an on-off switch but a tunable rheostat. Trends Immunol (2009) 30:143-9. doi:10.1016/j.it.2009.01.006

35. Brodin P, Lakshmikanth T, Johansson S, Kärre K, Höglund P. The strength of inhibitory input during education quantitatively tunes the functional responsiveness of individual natural killer cells. Blood (2009) 113:2434-41. doi:10.1182/blood-2008-05-156836

36. Joncker NT, Fernandez NC, Treiner E, Vivier E, Raulet DH. NK cell responsiveness is tuned commensurate with the number of inhibitory receptors for self-MHC class I: the rheostat model. J Immunol (2009) 182:4572-80. doi:10.4049/jimmunol.0803900

37. Elliott JM, Wahle JA, Yokoyama WM. MHC class I-deficient natural killer cells acquire a licensed phenotype after transfer into an MHC class I-sufficient environment. J Exp Med (2010) 207:2073-9. doi:10.1084/jem.20100986
38. Joncker NT, Shifrin N, Delebecque F, Raulet DH. Mature natural killer cells reset their responsiveness when exposed to an altered MHC environment. J Exp Med (2010) 207:2065-72. doi:10.1084/jem.20100570

39. Ebihara T, Jonsson AH, Yokoyama WM. Natural killer cell licensing in mice with inducible expression of MHC class I. Proc Natl Acad Sci U S A (2013) 110:E4232-7. doi:10.1073/pnas.1318255110

40. Lanier LL. Up on the tightrope: natural killer cell activation and inhibition. Nat Immunol (2008) 9:495-502. doi:10.1038/ni1581

41. Campbell KS, Purdy AK. Structure/function of human killer cell immunoglobulin-like receptors: lessons from polymorphisms, evolution, crystal structures and mutations. Immunology (2011) 132:315-25. doi:10.1111/j. 1365-2567.2010.03398.x

42. Yokoyama WM, Kim S. Licensing of natural killer cells by self-major histocompatibility complex class I. Immunol Rev (2006) 214:143-54. doi:10.1111/j. 1600-065X.2006.00458.x

43. Wang JW, Howson JM, Ghansah T, Desponts C, Ninos JM, May SL, et al. Influence of SHIP on the NK repertoire and allogeneic bone marrow transplantation. Science (2002) 295:2094-7. doi:10.1126/science.1068438

44. Fortenbery NR, Paraiso KHT, Taniguchi M, Brooks C, Ibrahim L, Kerr WG. SHIP influences signals from CD48 and MHC class I ligands that regulate NK cell homeostasis, effector function, and repertoire formation. J Immunol (2010) 184:5065-74. doi:10.4049/jimmunol.0901862

45. Lowin-Kropf B, Kunz B, Beermann F, Held W. Impaired natural killing of MHC class I-deficient targets by NK cells expressing a catalytically inactive form of SHP-1. J Immunol (2000) 165:1314-21.

46. Peterson ME, Long EO. Inhibitory receptor signaling via tyrosine phosphorylation of the adaptor Crk. Immunity (2008) 29:578-88. doi:10.1016/j.immuni. 2008.07.014

47. Liu D, Peterson ME, Long EO. The adaptor protein Crk controls activation and inhibition of natural killer cells. Immunity (2012) 36:600-11. doi:10.1016/j.immuni.2012.03.007

48. Thomas LM, Peterson ME, Long EO. Cutting edge: NK cell licensing modulates adhesion to target cells. J Immunol (2013) 191:3981-5. doi:10.4049/jimmunol. 1301159

49. Matsumoto G, Nghiem MP, Nozaki N, Schmits R, Penninger JM. Cooperation between CD44 and LFA-1/CD11a adhesion receptors in lymphokine-activated killer cell cytotoxicity. J Immunol (1998) 160:5781-9.

50. Matsumoto G, Omi Y, Lee U, Nishimura T, Shindo J, Penninger JM. Adhesion mediated by LFA-1 is required for efficient IL-12-induced NK and NKT cell cytotoxicity. Eur J Immunol (2000) 30:3723-31. doi:10.1002/15214141(200012)30:12<3723::AID-IMMU3723>3.0.CO;2-9

51. Bryceson YT, March ME, Barber DF, Ljunggren HG, Long EO. Cytolytic granule polarization and degranulation controlled by different receptors in resting NK cells. J Exp Med (2005) 202:1001-12. doi:10.1084/jem.20051143

52. Hogg N, Leitinger B. Shape and shift changes related to the function of leukocyte integrins LFA-1 and Mac-1. J Leukoc Biol (2001) 69:893-8.

53. Orange JS, Fassett MS, Koopman LA, Boyson JE, Strominger JL. Viral evasion of natural killer cells. Nat Immunol (2002) 3:1006-12. doi:10.1038/ni1102-1006

54. Jonjić S, Babić M, Polić B, Krmpotić A. Immune evasion of natural killer cells by viruses. Curr Opin Immunol (2008) 20:30-8. doi:10.1016/j.coi.2007.11.002

55. Jones TR, Wiertz EJ, Sun L, Fish KN, Nelson JA, Ploegh HL. Human cytomegalovirus US3 impairs transport and maturation of major histocompatibility complex class I heavy chains. Proc Natl Acad Sci U S A (1996) 93:11327-33. doi:10.1073/pnas.93.21.11327

56. Park B, Kim Y, Shin J, Lee S, Cho K, Früh K, et al. Human cytomegalovirus inhibits tapasin-dependent peptide loading and optimization of the MHC class I peptide cargo for immune evasion. Immunity (2004) 20:71-85. doi:10.1016/ S1074-7613(03)00355-8

57. Noriega VM, Hesse J, Gardner TJ, Besold K, Plachter B, Tortorella D. Human cytomegalovirus US3 modulates destruction of MHC class I molecules. Mol Immunol (2012) 51:245-53. doi:10.1016/j.molimm.2012.03.024

58. Lehner PJ, Karttunen JT, Wilkinson GW, Cresswell P. The human cytomegalovirus US6 glycoprotein inhibits transporter associated with antigen processing-dependent peptide translocation. Proc Natl Acad Sci U S A (1997) 94:6904-9. doi:10.1073/pnas.94.13.6904

59. Llano M, Gumá M, Ortega M, Angulo A, López-Botet M. Differential effects of US2, US6 and US11 human cytomegalovirus proteins on HLA class Ia 
and HLA-E expression: impact on target susceptibility to NK cell subsets. Eur J Immunol (2003) 33:2744-54. doi:10.1002/eji.200324182

60. Gewurz BE, Wang EW, Tortorella D, Schust DJ, Ploegh HL. Human cytomegalovirus US2 endoplasmic reticulum-lumenal domain dictates association with major histocompatibility complex class I in a locus-specific manner. J Virol (2001) 75:5197-204. doi:10.1128/JVI.75.11.5197-5204.2001

61. Schust DJ, Tortorella D, Seebach J, Phan C, Ploegh HL. Trophoblast class I major histocompatibility complex (MHC) products are resistant to rapid degradation imposed by the human cytomegalovirus (HCMV) gene products US2 and US11. J Exp Med (1998) 188:497-503. doi:10.1084/jem.188.3.497

62. Machold RP, Wiertz EJ, Jones TR, Ploegh HL. The HCMV gene products US11 and US2 differ in their ability to attack allelic forms of murine major histocompatibility complex (MHC) class I heavy chains. J Exp Med (1997) 185:363-6. doi:10.1084/jem.185.2.363

63. Schaefer MR, Wonderlich ER, Roeth JF, Leonard JA, Collins KL. HIV-1 Nef targets MHC-I and CD4 for degradation via a final common beta-COP-dependent pathway in T cells. PLoS Pathog (2008) 4:e1000131. doi:10.1371/journal.ppat. 1000131

64. Le Gall S, Erdtmann L, Benichou S, Berlioz-Torrent C, Liu L, Benarous R, et al. Nef interacts with the $\mu$ subunit of clathrin adaptor complexes and reveals a cryptic sorting signal in MHC I molecules. Immunity (1998) 8:483-95. doi:10.1016/S1074-7613(00)80553-1

65. Collins KL, Chen BK, Kalams SA, Walker BD, Baltimore D. HIV-1 Nef protein protects infected primary cells against killing by cytotoxic T lymphocytes. Nature (1998) 391:397-401. doi:10.1038/34929

66. Cohen GB, Gandhi RT, Davis DM, Mandelboim O, Chen BK, Strominger JL, et al. The selective downregulation of class I major histocompatibility complex proteins by HIV-1 protects HIV-infected cells from NK cells. Immunity (1999) 10:661-71. doi:10.1016/S1074-7613(00)80065-5

67. Flores-Villanueva PO, Yunis EJ, Delgado JC, Vittinghoff E, Buchbinder S, Leung JY, et al. Control of HIV-1 viremia and protection from AIDS are associated with HLA-Bw4 homozygosity. Proc Natl Acad Sci U S A (2001) 98:5140-5. doi:10.1073/pnas.071548198

68. Martin MP, Qi Y, Gao X, Yamada E, Nolte MA, Pereyra F, et al. Innate partnership of HLA-B and KIR3DL1 subtypes against HIV-1. Nat Genet (2007) 39:733-40. doi:10.1038/ng2035

69. Tomescu C, Duh FM, Hoh R, Viviani A, Harvill K, Martin MP, et al. Impact of protective killer inhibitory receptor/human leukocyte antigen genotypes on natural killer cell and T-cell function in HIV-1-infected controllers. AIDS (2012) 26:1869-78. doi:10.1097/QAD.0b013e32835861b0

70. Rajapaksa US, Li D, Peng YC, McMichael AJ, Dong T, Xu XN. HLA-B may be more protective against HIV-1 than HLA-A because it resists negative regulatory factor (Nef) mediated down-regulation. Proc Natl Acad Sci U S A (2012) 109:13353-8. doi:10.1073/pnas.1204199109

71. Dasgupta A, Hammarlund E, Slifka MK, Früh K. Cowpox virus evades CTL recognition and inhibits the intracellular transport of MHC class I molecules. J Immunol (2007) 178:1654-61.

72. Byun M, Wang X, Pak M, Hansen TH, Yokoyama WM. Cowpox virus exploits the endoplasmic reticulum retention pathway to inhibit MHC class I transport to the cell surface. Cell Host Microbe (2007) 2:306-15. doi:10.1016/j.chom. 2007.09.002

73. Alzhanova D, Edwards DM, Hammarlund E, Scholz IG, Horst D, Wagner MJ, et al. Cowpox virus inhibits the transporter associated with antigen processing to evade T cell recognition. Cell Host Microbe (2009) 6:433-45. doi:10.1016/j.chom.2009.09.013

74. McCoy WH IV, Wang X, Yokoyama WM, Hansen TH, Fremont DH. Cowpox virus employs a two-pronged strategy to outflank MHCI antigen presentation. Mol Immunol (2013) 55:156-8. doi:10.1016/j.molimm.2012.11.011

75. Tomasec P, Braud VM, Rickards C, Powell MB, McSharry BP, Gadola S, et al. Surface expression of HLA-E, an inhibitor of natural killer cells, enhanced by human cytomegalovirus gpUL40. Science (2000) 287:1031-3. doi:10.1126/ science.287.5455.1031

76. Ulbrecht M, Martinozzi S, Grzeschik M, Hengel H, Ellwart JW, Pla M, et al. Cutting edge: the human cytomegalovirus UL40 gene product contains a ligand for HLA-E and prevents NK cell-mediated lysis. J Immunol (2000) 164: 5019-22.

77. Heatley SL, Pietra G, Lin J, Widjaja JM, Harpur CM, Lester S, et al. Polymorphism in human cytomegalovirus UL40 impacts on recognition of human leukocyte antigen-E (HLA-E) by natural killer cells. J Biol Chem (2013) 288:8679-90. doi:10.1074/jbc.M112.409672

78. Ziegler H, Thäle R, Lucin P, Muranyi W, Flohr T, Hengel H, et al. A mouse cytomegalovirus glycoprotein retains MHC class I complexes in the ERGIC/cisGolgi compartments. Immunity (1997) 6:57-66. doi:10.1016/S1074-7613(00) 80242-3

79. Reusch U, Muranyi W, Lucin P, Burgert HG, Hengel H, Koszinowski UH. A cytomegalovirus glycoprotein re-routes MHC class I complexes to lysosomes for degradation. EMBO J (1999) 18:1081-91. doi:10.1093/emboj/18.4.1081

80. Kleijnen MF, Huppa JB, Lucin P, Mukherjee S, Farrell H, Campbell AE, et al. A mouse cytomegalovirus glycoprotein, gp34, forms a complex with folded class I MHC molecules in the ER which is not retained but is transported to the cell surface. EMBO J (1997) 16:685-94. doi:10.1093/emboj/16.4.685

81. Kavanagh DG, Gold MC, Wagner M, Koszinowski UH, Hill AB. The multiple immune-evasion genes of murine cytomegalovirus are not redundant: $\mathrm{m} 4$ and m152 inhibit antigen presentation in a complementary and cooperative fashion. J Exp Med (2001) 194:967-78. doi:10.1084/jem.194.7.967

82. Xie X, Dighe A, Clark P, Sabastian P, Buss S, Brown MG. Deficient major histocompatibility complex-linked innate murine cytomegalovirus immunity in MA/My.L-H2b mice and viral downregulation of H-2k class I proteins. J Virol (2007) 81:229-36. doi:10.1128/JVI.00997-06

83. Wagner M, Gutermann A, Podlech J, Reddehase MJ, Koszinowski UH. Major histocompatibility complex class I allele-specific cooperative and competitive interactions between immune evasion proteins of cytomegalovirus. J Exp Med (2002) 196:805-16. doi:10.1084/jem.20020811

84. Pinto AK, Munks MW, Koszinowski UH, Hill AB. Coordinated function of murine cytomegalovirus genes completely inhibits CTL lysis. J Immunol (2006) 177:3225-34.

85. Babić M, Pyzik M, Zafirova B, Mitrović M, Butorac V, Lanier LL, et al. Cytomegalovirus immunoevasin reveals the physiological role of "missing self" recognition in natural killer cell dependent virus control in vivo. J Exp Med (2010) 207:2663-73. doi:10.1084/jem.20100921

86. Corbett AJ, Forbes CA, Moro D, Scalzo AA. Extensive sequence variation exists among isolates of murine cytomegalovirus within members of the m02 family of genes. J Gen Virol (2007) 88:758-69. doi:10.1099/vir.0.82623-0

87. Cheng TP, Valentine MC, Gao J, Pingel JT, Yokoyama WM. Stability of murine cytomegalovirus genome after in vitro and in vivo passage. J Virol (2010) 84:2623-8. doi:10.1128/JVI.02142-09

88. Cullen BR. MicroRNAs as mediators of viral evasion of the immune system. Nat Immunol (2013) 14:205-10. doi:10.1038/ni.2537

89. Elias S, Mandelboim O. Battle of the midgets: innate microRNA networking. RNA Biol (2012) 9:792-8. doi:10.4161/rna.19717

90. Stern-Ginossar N, Elefant N, Zimmermann A, Wolf DG, Saleh N, Biton M, et al. Host immune system gene targeting by a viral miRNA. Science (2007) 20:376-81. doi:10.1126/science.1140956

91. Nachmani D, Stern-Ginossar N, Sarid R, Mandelboim O. Diverse herpesvirus microRNAs target the stress-induced immune ligand MICB to escape recognition by natural killer cells. Cell Host Microbe (2009) 5:376-85. doi:10.1016/j. chom.2009.03.003

92. Prod'homme V, Griffin C, Aicheler RJ, Wang EC, McSharry BP, Rickards CR, et al. The human cytomegalovirus MHC class I homolog UL18 inhibits LIR-1+ but activates LIR-1 - NK cells. J Immunol (2007) 178:4473-81.

93. Campbell JA, Trossman DS, Yokoyama WM, Carayannopoulos LN. Zoonotic orthopoxviruses encode a high-affinity antagonist of NKG2D. J Exp Med (2007) 204:1311-7. doi:10.1084/jem.20062026

94. Cretney E, Degli-Esposti MA, Densley EH, Farrell HE, Davis-Poynter NJ, Smyth MJ. m144, a murine cytomegalovirus (MCMV)-encoded major histocompatibility complex class I homologue, confers tumor resistance to natural killer cellmediated rejection. J Exp Med (1999) 190:435-44. doi:10.1084/jem.190.3.435

95. Kubota A, Kubota S, Farrell HE, Davis-Poynter N, Takei F. Inhibition of NK cells by murine CMV-encoded class I MHC homologue m144. Cell Immunol (1999) 191:145-51. doi:10.1006/cimm.1998.1424

96. Natarajan K, Hicks A, Mans J, Robinson H, Guan R, Mariuzza RA, et al. Crystal structure of the murine cytomegalovirus MHC-I homolog m144. J Mol Biol (2006) 358:157-71. doi:10.1016/j.jmb.2006.01.068

97. Farrell HE, Vally H, Lynch DM, Fleming P, Shellam GR, Scalzo AA, et al. Inhibition of natural killer cells by a cytomegalovirus MHC class I homologue in vivo. Nature (1997) 386:510-4. doi:10.1038/386510a0 
98. Smith HR, Heusel JW, Mehta IK, Kim S, Dorner BG, Naidenko OV, et al. Recognition of a virus-encoded ligand by a natural killer cell activation receptor. Proc Natl Acad Sci U S A (2002) 99:8826-31. doi:10.1073/pnas.092258599

99. Arase H, Mocarski ES, Campbell AE, Hill AB, Lanier LL. Direct recognition of cytomegalovirus by activating and inhibitory NK cell receptors. Science (2002) 296:1323-6. doi:10.1126/science.1070884

100. Corbett AJ, Coudert JD, Forbes CA, Scalzo AA. Functional consequences of natural sequence variation of murine cytomegalovirus m157 for Ly49 receptor specificity and NK cell activation. J Immunol (2011) 186:1713-22. doi:10.4049/jimmunol.1003308

101. Adams EJ, Juo ZS, Venook RT, Boulanger MJ, Arase H, Lanier LL, et al. Structural elucidation of the m157 mouse cytomegalovirus ligand for Ly49 natural killer cell receptors. Proc Natl Acad Sci U S A (2007) 104:10128-33. doi:10.1073/pnas.0703735104

102. Berry R, Ng N, Saunders PM, Vivian JP, Lin J, Deuss FA, et al. Targeting of a natural killer cell receptor family by a viral immunoevasin. Nat Immunol (2013) 14:699-705. doi:10.1038/ni.2605

103. Bubić I, Wagner M, Krmpotić A, Saulig T, Kim S, Yokoyama WM, et al. Gain of virulence caused by loss of a gene in murine cytomegalovirus. J Virol (2004) 78:7536-44. doi:10.1128/JVI.78.14.7536-7544.2004

104. Brown MG, Dokun AO, Heusel JW, Smith HR, Beckman DL, Blattenberger $\mathrm{EA}$, et al. Vital involvement of a natural killer cell activation receptor in resistance to viral infection. Science (2001) 292:934-7. doi:10.1126/science. 1060042

105. Daniels KA, Devora G, Lai WC, O’Donnell CL, Bennett M, Welsh RM. Murine cytomegalovirus is regulated by a discrete subset of natural killer cells reactive with monoclonal antibody to Ly49H. J Exp Med (2001) 194:29-44. doi:10.1084/jem.194.1.29

106. Lee SH, Girard S, Macina D, Busà M, Zafer A, Belouchi A, et al. Susceptibility to mouse cytomegalovirus is associated with deletion of an activating natural killer cell receptor of the C-type lectin superfamily. Nat Genet (2001) 28:42-5. doi:10.1038/ng0501-42

107. Makrigiannis AP, Pau AT, Saleh A, Winkler-Pickett R, Ortaldo JR, Anderson SK. Class I MHC-binding characteristics of the 129/J Ly49 repertoire. J Immunol (2001) 166:5034-43.

108. Lanier LL. Evolutionary struggles between NK cells and viruses. Nat Rev Immunol (2008) 8:259-68. doi:10.1038/nri2276

109. Miletić A, Krmpotić A, Jonjić S. The evolutionary arms race between NK cells and viruses: who gets the short end of the stick? Eur J Immunol (2013) 43:867-77. doi:10.1002/eji.201243101

110. Sun JC, Lanier LL. The natural selection of herpesviruses and virus-specific NK cell receptors. Viruses (2009) 1:362-82. doi:10.3390/v1030362

111. Carrillo-Bustamante P, Kesmir C, de Boer RJ. Virus encoded MHC-like decoys diversify the inhibitory KIR repertoire. PLoS Comput Biol (2013) 9:e1003264. doi:10.1371/journal.pcbi.1003264

112. Mandelboim O, Lieberman N, Lev M, Paul L, Arnon TI, Bushkin Y, et al. Recognition of haemagglutinins on virus-infected cells by NKp46 activates lysis by human NK cells. Nature (2001) 409:1055-60. doi:10.1038/35059110

113. Kielczewska A, Pyzik M, Sun T, Krmpotic A, Lodoen MB, Munks MW, et al Ly49P recognition of cytomegalovirus-infected cells expressing $\mathrm{H} 2-\mathrm{D}^{\mathrm{k}}$ and CMV-encoded m04 correlates with the NK cell antiviral response. J Exp Med (2009) 206:515-23. doi:10.1084/jem.20080954

114. Jarahian M, Fiedler M, Cohnen A, Djandji D, Hämmerling GJ, Gati C, et al. Modulation of NKp30- and NKp46-mediated natural killer cell responses by poxviral hemagglutinin. PLoS Pathog (2011) 7:e1002195. doi:10.1371/journal. ppat. 1002195

115. Magri G, Muntasell A, Romo N, Sáez-Borderías A, Pende D, Geraghty DE, et al. NKp46 and DNAM-1 NK-cell receptors drive the response to human cytomegalovirus-infected myeloid dendritic cells overcoming viral immune evasion strategies. Blood (2011) 117:848-56. doi:10.1182/blood-2010-08301374

116. Chaigne-Delalande B, Li FY, O'Connor GM, Lukacs MJ, Jiang P, Zheng L, et al. $\mathrm{Mg} 2+$ regulates cytotoxic functions of NK and CD8 T cells in chronic EBV infection through NKG2D. Science (2013) 341:186-91. doi:10.1126/science. 1240094

117. Gumá M, Angulo A, Vilches C, Gómez-Lozano N, Malats N, López-Botet M. Imprint of human cytomegalovirus infection on the NK cell receptor repertoire. Blood (2004) 104:3664-71. doi:10.1182/blood-2004-05-2058
118. Tay CH, Yu LY, Kumar V, Mason L, Ortaldo JR, Welsh RM. The role of LY49 NK cell subsets in the regulation of murine cytomegalovirus infections. J Immunol (1999) 162:718-26.

119. Makrigiannis AP, Rousselle E, Anderson SK. Independent control of Ly49g alleles: implications for NK cell repertoire selection and tumor cell killing. J Immunol (2004) 172:1414-25.

120. Barao I, Alvarez M, Ames E, Orr MT, Stefanski HE, Blazar BR, et al. Mouse Ly49G2 + NK cells dominate early responses during both immune reconstitution and activation independently of MHC. Blood (2011) 117:7032-41. doi:10.1182/blood-2010-11-316653

121. Barao I, Wright PW, Sungur CM, Anderson SK, Redelman D, Murphy WJ. Differential expression of the Ly49GB6, but not the Ly49G(BALB), receptor isoform during natural killer cell reconstitution after hematopoietic stem cell transplantation. Biol Blood Marrow Transplant (2013) 19:1446-52. doi:10.1016/j.bbmt.2013.07.021

122. Xie X, Stadnisky MD, Brown MG. MHC class I D(k) locus and Ly49G2+ NK cells confer H-2k resistance to murine cytomegalovirus. J Immunol (2009) 182:7163-71. doi:10.4049/jimmunol.0803933

123. Xie X, Stadnisky MD, Coats ER, Ahmed Rahim MM, Lundgren A, Xu W, et al. MHC class I D $(\mathrm{k})$ expression in hematopoietic and nonhematopoietic cells confers natural killer cell resistance to murine cytomegalovirus. Proc Natl Acad Sci U S A (2010) 107:8754-9. doi:10.1073/pnas.0913126107

124. Prince J, Lundgren A, Stadnisky MD, Nash WT, Beeber A, Turner SD, et al. Multiparametric analysis of host response to murine cytomegalovirus in $\mathrm{MHC}$ class I-disparate mice reveals primacy of $\mathrm{D}(\mathrm{k})$-licensed Ly49G2 + NK cells in viral control. J Immunol (2013) 191:4709-19. doi:10.4049/jimmunol.1301388

125. Mela CM, Burton CT, Imami N, Nelson M, Steel A, Gazzard BG, et al. Switch from inhibitory to activating NKG2 receptor expression in HIV-1 infection: lack of reversion with highly active antiretroviral therapy. AIDS (2005) 19:1761-9. doi:10.1097/01.aids.0000183632.12418.33

126. Gumá M, Cabrera C, Erkizia I, Bofill M, Clotet B, Ruiz L, et al. Human cytomegalovirus infection is associated with increased proportions of NK cells that express the CD94/NKG2C receptor in aviremic HIV-1-positive patients. J Infect Dis (2006) 194:38-41. doi:10.1086/504719

127. Lopez-Vergès S, Milush JM, Schwartz BS, Pando MJ, Jarjoura J, York VA, et al. Expansion of a unique CD57+NKG2Chi natural killer cell subset during acute human cytomegalovirus infection. Proc Natl Acad Sci U S A (2011) 108:14725-32. doi:10.1073/pnas.1110900108

128. Foley B, Cooley S, Verneris MR, Pitt M, Curtsinger J, Luo X, et al. Cytomegalovirus reactivation after allogeneic transplantation promotes a lasting increase in educated $\mathrm{NKG} 2 \mathrm{C}+$ natural killer cells with potent function. Blood (2012) 119:2665-74. doi:10.1182/blood-2011-10-386995

129. Béziat V, Liu LL, Malmberg JA, Ivarsson MA, Sohlberg E, Björklund AT, et al. NK cell responses to cytomegalovirus infection lead to stable imprints in the human KIR repertoire and involve activating KIRs. Blood (2013) 121:2678-88. doi:10.1182/blood-2012-10-459545

130. Charoudeh HN, Terszowski G, Czaja K, Gonzalez A, Schmitter K, Stern M. Modulation of the natural killer cell KIR repertoire by cytomegalovirus infection. Eur J Immunol (2013) 43:480-7. doi:10.1002/eji.201242389

131. Muntasell A, Vilches C, Angulo A, López-Botet M. Adaptive reconfiguration of the human NK-cell compartment in response to cytomegalovirus: a different perspective of the host-pathogen interaction. Eur J Immunol (2013) 43:1133-41. doi:10.1002/eji.201243117

132. Björkström NK, Lindgren T, Stoltz M, Fauriat C, Braun M, Evander M, et al. Rapid expansion and long-term persistence of elevated NK cell numbers in humans infected with hantavirus. J Exp Med (2011) 208:13-21. doi:10.1084/jem.20100762

133. Petitdemange C, Becquart P, Wauquier N, Béziat V, Debré P, Leroy EM, et al. Unconventional repertoire profile is imprinted during acute chikungunya infection for natural killer cells polarization toward cytotoxicity. PLoS Pathog (2011) 7:e1002268. doi:10.1371/journal.ppat.1002268

134. Gregson JNS, Kuri-Cervantes L, Mela CM, Gazzard BG, Bower M, Goodier MR. Short communication: NKG2C $+\mathrm{NK}$ cells contribute to increases in CD16+CD56- cells in HIV type 1+ individuals with high plasma viral load. AIDS Res Hum Retroviruses (2013) 29:84-8. doi:10.1089/AID.2011.0397

135. Béziat V, Dalgard O, Asselah T, Halfon P, Bedossa P, Boudifa A, et al. CMV drives clonal expansion of NKG2C+ NK cells expressing self-specific KIRs in chronic hepatitis patients. Eur J Immunol (2012) 42:447-57. doi:10.1002/eji.201141826 
136. Saghafian-Hedengren S, Sohlberg E, Theorell J, Carvalho-Queiroz C, Nagy $\mathrm{N}$, Persson JO, et al. Epstein-Barr virus coinfection in children boosts cytomegalovirus-induced differentiation of natural killer cells. J Virol (2013) 87:13446-55. doi:10.1128/JVI.02382-13

137. Alter G, Rihn S, Walter K, Nolting A, Martin M, Rosenberg ES, et al. HLA class I subtype-dependent expansion of KIR3DS1+ and KIR3DL1+ NK cells during acute human immunodeficiency virus type 1 infection. J Virol (2009) 83:6798-805. doi:10.1128/JVI.00256-09

138. Pelak K, Need AC, Fellay J, Shianna KV, Feng S, Urban TJ, et al. Copy number variation of KIR genes influences HIV-1 control. PLoS Biol (2011) 9:e1001208. doi:10.1371/journal.pbio.1001208

139. Brown MG, Scalzo AA. NK gene complex dynamics and selection for NK cell receptors. Semin Immunol (2008) 20:361-8. doi:10.1016/j.smim.2008.06.004

140. Dokun AO, Kim S, Smith HR, Kang HS, Chu DT, Yokoyama WM. Specific and nonspecific NK cell activation during virus infection. Nat Immunol (2001) 2:951-6. doi:10.1038/ni714

141. Scalzo AA, Lyons PA, Fitzgerald NA, Forbes CA, Yokoyama WM, Shellam GR. Genetic mapping of Cmvl in the region of mouse chromosome 6 encoding the NK gene complex-associated loci Ly49 and mus NKR-P1. Gene Ther (1995) 27:435-41. doi:10.1006/geno.1995.1074

142. Brown M, Scalzo A, Stone L, Clark P, Du Y, Palanca B, et al. Natural killer gene complex (Nkc) allelic variability in inbred mice: evidence for Nkc haplotypes. Immunogenetics (2001) 53:584-91. doi:10.1007/s002510100365

143. Desrosiers MP, Kielczewska A, Loredo-Osti JC, Adam SG, Makrigiannis AP, Lemieux S, et al. Epistasis between mouse Klra and major histocompatibility complex class I loci is associated with a new mechanism of natural killer cell-mediated innate resistance to cytomegalovirus infection. Nat Genet (2005) 37:593-9. doi:10.1038/ng1564

144. Dighe A, Rodriguez M, Sabastian P, Xie X, McVoy M, Brown MG. Requisite H2k role in NK cell-mediated resistance in acute murine cytomegalovirus-infected MA/My mice. J Immunol (2005) 175:6820-8.

145. Fodil-Cornu N, Loredo-Osti JC, Vidal SM. NK cell receptor/H2-D $\mathrm{D}^{\mathrm{k}}$-dependent host resistance to viral infection is quantitatively modulated by $\mathrm{H} 2 \mathrm{q}$ inhibitory signals. PLoS Genet (2011) 7:e1001368. doi:10.1371/journal.pgen.1001368

146. Orr MT, Murphy WJ, Lanier LL. "Unlicensed" natural killer cells dominate the response to cytomegalovirus infection. Nat Immunol (2010) 11:321-7. doi:10.1038/ni.1849

147. Sungur CM, Tang-Feldman YJ, Ames E, Alvarez M, Chen M, Longo DL, et al. Murine natural killer cell licensing and regulation by $\mathrm{T}$ regulatory cells in viral responses. Proc Natl Acad Sci U S A (2013) 110:7401-6. doi:10.1073/pnas. 1218767110

148. Sungur CM, Tang-Feldman YJ, Zamora AE, Alvarez M, Pomeroy C, Murphy WJ. Murine NK-cell licensing is reflective of donor MHC-I following allogeneic hematopoietic stem cell transplantation in murine cytomegalovirus responses. Blood (2013) 122:1518-21. doi:10.1182/blood-2013-02-483503

149. Wu MF, Raulet DH. Class I-deficient hemopoietic cells and nonhemopoietic cells dominantly induce unresponsiveness of natural killer cells to class I-deficient bone marrow cell grafts. J Immunol (1997) 158:1628-33.

150. Johansson MH, Bieberich C, Jay G, Kärre K, Höglund P. Natural killer cell tolerance in mice with mosaic expression of major histocompatibility complex class I transgene. J Exp Med (1997) 186:353-64. doi:10.1084/jem.186.3.353

151. Haas P, Loiseau P, Tamouza R, Cayuela JM, Moins-Teisserenc H, Busson M, et al. NK-cell education is shaped by donor HLA genotype after unrelated allogeneic hematopoietic stem cell transplantation. Blood (2011) 117:1021-9. doi:10.1182/blood-2010-02-269381

152. Brooks CR, Elliott T, Parham P, Khakoo SI. The inhibitory receptor NKG2A determines lysis of vaccinia virus-infected autologous targets by NK cells. J Immunol (2006) 176:1141-7.

153. Jamil KM, Khakoo SI. KIR/HLA interactions and pathogen immunity. JBiomed Biotechnol (2011) 2011:e298348. doi:10.1155/2011/298348

154. Fadda L, O’Connor GM, Kumar S, Piechocka-Trocha A, Gardiner CM, Carrington $\mathrm{M}$, et al. Common HIV-1 peptide variants mediate differential binding of KIR3DL1 to HLA-Bw4 molecules. J Virol (2011) 85:5970-4. doi:10.1128/ JVI.00412-11
155. Alter G, Altfeld M. NK cells in HIV-1 infection: evidence for their role in the control of HIV-1 infection. J Intern Med (2009) 265:29-42. doi:10.1111/j.13652796.2008.02045.x

156. Thomas R, Apps R, Qi Y, Gao X, Male V, O'hUigin C, et al. HLA-C cell surface expression and control of HIV/AIDS correlate with a variant upstream of HLA-C. Nat Genet (2009) 41:1290-4. doi:10.1038/ng.486

157. Ballana E, Ruiz-de Andres A, Mothe B, Ramirez de Arellano E, Aguilar F, Badia $\mathrm{R}$, et al. Differential prevalence of the HLA-C - 35 CC genotype among viremic long term non-progressor and elite controller HIV+ individuals. Immunity (2012) 217:889-94. doi:10.1016/j.imbio.2011.12.012

158. Charoudeh H, Schmied L, Gonzalez A, Terszowski G, Czaja K, Schmitter K, et al. Quantity of HLA-C surface expression and licensing of KIR2DL+ natural killer cells. Immunogenetics (2012) 64:739-45. doi:10.1007/s00251-012-0633-1

159. Apps R, Qi Y, Carlson JM, Chen H, Gao X, Thomas R, et al. Influence of HLAC expression level on HIV control. Science (2013) 340:87-91. doi:10.1126/ science. 1232685

160. Kulkarni S, Qi Y, O’hUigin C, Pereyra F, Ramsuran V, McLaren P, et al. Genetic interplay between HLA-C and MIR148A in HIV control and Crohn disease. Proc Natl Acad Sci U S A (2013) 110:20705-10. doi:10.1073/pnas.1312237110

161. Alter G, Heckerman D, Schneidewind A, Fadda L, Kadie CM, Carlson JM, et al. HIV-1 adaptation to NK-cell-mediated immune pressure. Nature (2011) 476:96-100. doi:10.1038/nature10237

162. Fadda L, Körner C, Kumar S, van Teijlingen NH, Piechocka-Trocha A, Carrington $\mathrm{M}$, et al. HLA-Cw ${ }^{*} 0102$-restricted HIV-1 p24 epitope variants can modulate the binding of the inhibitory KIR2DL2 receptor and primary NK cell function. PLoS Pathog (2012) 8:e1002805. doi:10.1371/journal.ppat.1002805

163. Amadei B, Urbani S, Cazaly A, Fisicaro P, Zerbini A, Ahmed P, et al. Activation of natural killer cells during acute infection with hepatitis $\mathrm{C}$ virus. Gastroenterology (2010) 138:1536-45. doi:10.1053/j.gastro.2010.01.006

164. Khakoo SI. HLA and NK cell inhibitory receptor genes in resolving hepatitis C virus infection. Science (2004) 305:872-4. doi:10.1126/science.1097670

165. Romero V, Azocar J, Zúñiga J, Clavijo OP, Terreros D, Gu X, et al. Interaction of NK inhibitory receptor genes with HLA-C and MHC class II alleles in hepatitis C virus infection outcome. Mol Immunol (2008) 45:2429-36. doi:10.1016/j.molimm.2008.01.002

166. Knapp S, Warshow U, Hegazy D, Brackenbury L, Guha IN, Fowell A, et al. Consistent beneficial effects of killer cell immunoglobulin-like receptor 2DL3 and group 1 human leukocyte antigen-C following exposure to hepatitis $\mathrm{C}$ virus. Hepatology (2010) 51:1168-75. doi:10.1002/hep.23477

167. Ahlenstiel G, Martin MP, Gao X, Carrington M, Rehermann B. Distinct KIR/HLA compound genotypes affect the kinetics of human antiviral natural killer cell responses. J Clin Invest (2008) 118:1017-26. doi:10.1172/JCI32400

168. La D, Czarnecki C, El-Gabalawy H, Kumar A, Meyers AF, Bastien N, et al. Enrichment of variations in KIR3DL1/S1 and KIR2DL2/L3 among H1N1/09 ICU patients: an exploratory study. PLoS One (2011) 6:e29200. doi:10.1371/ journal.pone.0029200

Conflict of Interest Statement: The authors declare that the research was conducted in the absence of any commercial or financial relationships that could be construed as a potential conflict of interest.

Received: 29 January 2014; paper pending published: 03 March 2014; accepted: 03 April 2014; published online: 16 April 2014.

Citation: Nash WT, Teoh J, Wei H, Gamache A and Brown MG (2014) Know thyself: NK-cell inhibitory receptors prompt self-tolerance, education, and viral control. Front. Immunol. 5:175. doi: 10.3389/fimmu.2014.00175

This article was submitted to Molecular Innate Immunity, a section of the journal Frontiers in Immunology.

Copyright (C) 2014 Nash, Teoh, Wei, Gamache and Brown. This is an open-access article distributed under the terms of the Creative Commons Attribution License (CC $B Y)$. The use, distribution or reproduction in other forums is permitted, provided the original author(s) or licensor are credited and that the original publication in this journal is cited, in accordance with accepted academic practice. No use, distribution or reproduction is permitted which does not comply with these terms. 